\title{
Synthesis and coordination ability of a partially silicon based crown ether $\dagger$
}

Cite this: Chem. Commun., 2016, 52, 13265

Received 14th September 2016, Accepted 14th October 2016

\author{
Kirsten Reuter, ${ }^{a}$ Günther Thiele, ${ }^{b}$ Thomas Hafner, ${ }^{c}$ Frank Uhlig ${ }^{c}$ and \\ Carsten von Hänisch*a
}

DOI: $10.1039 / \mathrm{c} 6 \mathrm{cc} 07520 \mathrm{~g}$

www.rsc.org/chemcomm

The first hybrid crown ether with two adjacent disilane fragments was synthesized through reaction of $\mathrm{O}\left(\mathrm{Si}_{2} \mathrm{Me}_{4} \mathrm{Cl}\right)_{2}$ (3) with $\mathrm{O}\left(\mathrm{C}_{2} \mathrm{H}_{4} \mathrm{OH}\right)_{2}$. By means of DFT calculations, the complexation ability of $1,2,4,5$ tetrasila[12]crown-4 (7) towards $\mathrm{Li}^{+}$was determined to be considerably higher compared to [12]crown-4.

Compared to ethers, siloxanes show low coordination ability towards Lewis acids. ${ }^{1}$ This has been attributed to both electronic and structural effects: the electron density of the $\mathrm{O}$ atom is less available as a result of the interaction between the lone pairs of the $\mathrm{O}$ atom and the $\sigma^{*}$-orbitals of the $\mathrm{Si}-\mathrm{C}$ bonds. ${ }^{2}$ This negative hyperconjugation is then not only competing with the coordination of a cation, it also leads to a widening of the Si-O bond angle. ${ }^{3} \mathrm{On}$ the other hand, the ionic character of the $\mathrm{Si}-\mathrm{O}$ bond increases with larger $\mathrm{Si}-\mathrm{O}$ angles. ${ }^{4}$ The high anionicity of the $\mathrm{O}$ atom would rather suggest an increased coordination ability. This is especially not the case for linear $\mathrm{Si}-\mathrm{O}$ linkages, which can be related to the delocalized and hardly polarizable electron density at the $\mathrm{O}$ atom. ${ }^{5}$ Additionally, recent studies revealed that the positively polarized $\mathrm{Si}$ atoms in siloxanes show a considerable repulsion towards cations. ${ }^{6}$

Lately, we reported on hybrid crown ethers which partially incorporate a disilane and an ethylene framework (Scheme 1). ${ }^{7}$ The presence of $\mathrm{Si}_{2}$-units leads to a structural equivalence of organic and inorganic fragments with respect to the number of atoms between the donor atom. By DFT calculations and dynamic proton NMR studies, the stability of these hybrid disila-crown ethers complexes was determined to be in the range of organic crown ether complexes. Unexpectedly, the insertion of disilane units does not reduce the coordination ability of the ligand as has been

\footnotetext{
${ }^{a}$ Fachbereich Chemie and Wissenschaftliches Zentrum für Materialwissenschaften (WZMW), Philipps-Universität Marburg, Hans-Meerwein-Straße 4, 35043 Marburg, Germany.E-mail: haenisch@chemie.uni-marburg.de; Fax: +49-6421-2825653

${ }^{b}$ Department of Chemistry, University of California, 210 Lewis Hall, Berkeley, California 94720, USA

${ }^{c}$ Institut für Anorganische Chemie, TU Graz, $6330 \mathrm{Graz}$, Austria

$\dagger$ Electronic supplementary information (ESI) available: Experimental details, computational and crystallographic data. CCDC 1499542 (7) and 1499541 (8). For ESI and crystallographic data in CIF or other electronic format see DOI: 10.1039/c6cc07520g
}
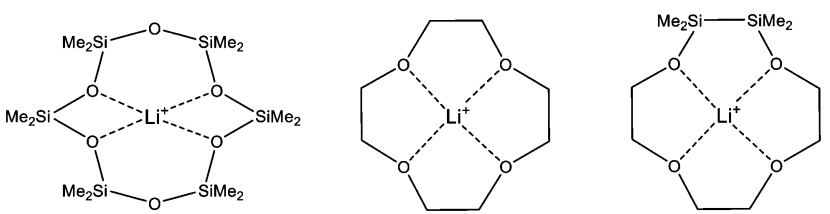

Scheme 1 Binding modes of $\mathrm{Li}^{+}$in $\mathrm{D}_{6}\left(\mathrm{D}=\mathrm{Me}_{2} \mathrm{SiO}\right.$ ) (left), [12]crown-4 (centre) and 1,2-disila[12]crown-4 (right) with increasing complex stability from left to right.

observed for ring contracted crown ethers like [17]crown- 6 and sila[17]crown-6. ${ }^{8}$ However, all hitherto described disila-crown ethers incorporate fully $\mathrm{C}$ or half $\mathrm{C}$ and half $\mathrm{Si}$ affected donor atoms. ${ }^{7}$ In this work, we report on the synthesis and the complex stability of a novel crown ether bearing organic, hybrid and fully inorganic substituted $\mathrm{O}$ atoms.

A suitable synthesis path for the required inorganic fragment, $\mathrm{O}\left(\mathrm{Si}_{2} \mathrm{Me}_{4} \mathrm{Cl}\right)_{2}(3)$, starts with the asymmetric chlorination of 1,1,2,2tetramethyldisilane by the use of trichloroisocyanuric acid (TCCA) (Scheme 2). ${ }^{9}$ The chlorination of the two Si atoms appears not to happen statistically. The distribution of the three resulting disilane species can be estimated from comparison of the intensities of the respective similar substituted $\mathrm{Si}$ atoms in the ${ }^{29} \mathrm{Si} \mathrm{NMR}$ spectrum (Fig. 1). $10 \%$ of $\mathrm{H}_{2} \mathrm{Si}_{2} \mathrm{Me}_{4}$ (I), $70 \%$ of $\mathrm{HSi}_{2} \mathrm{Me}_{4} \mathrm{Cl}$ (1) and $20 \%$ of $\mathrm{Cl}_{2} \mathrm{Si}_{2} \mathrm{Me}_{4}$ (II) can thusly be detected in the reaction solution. Since a small excess of TCCA has been used, the proportion of I and II is not precisely equal. After distillative purification, $64 \%$ of the asymmetrically chlorinated species $\mathbf{1}$ was obtained.

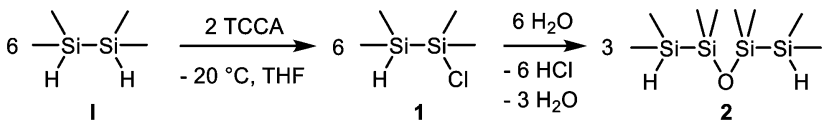

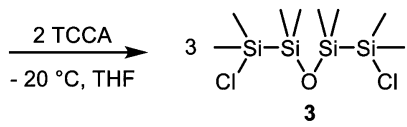

Scheme 2 Synthesis path for the inorganic building block of a partially $\mathrm{Si}$ based crown ether. 


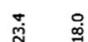

1

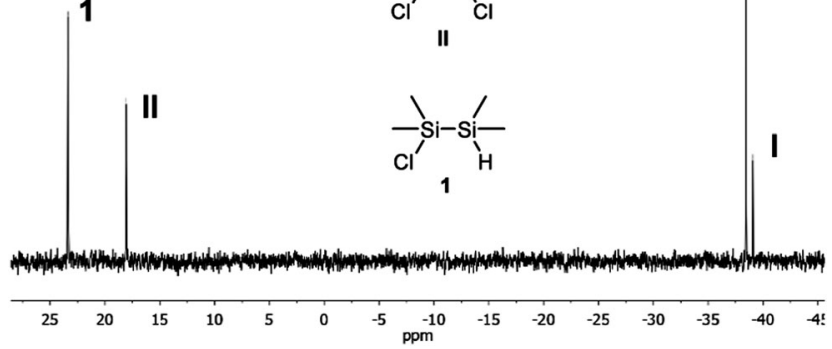

Fig. $1{ }^{29} \mathrm{Si}\{\mathrm{H}\}$ NMR spectrum $\left(\mathrm{D}_{2} \mathrm{O}\right.$-capillary, $59.60 \mathrm{MHz}$, DEPT) of the formation of $\mathrm{HSi}_{2} \mathrm{Me}_{4} \mathrm{Cl}$ after removal of the cyanuric acid.

Through treatment with water, compound 1 hydrolysed and condensed immediately in a clean reaction to $\mathrm{O}\left(\mathrm{Si}_{2} \mathrm{Me}_{4} \mathrm{H}\right)_{2}$ (2). In case of impurities, 2 was purified via distillation (b.p. $86{ }^{\circ} \mathrm{C}$, $10 \mathrm{mmHg}$ ). In the next step, the remaining $\mathrm{H}$ atoms at the terminal Si atoms were again substituted by the use of TCCA. In this reaction, the purity of the educt $\mathbf{2}$ is crucial, since 3 cannot be purified by distillation as a result of its low decomposition temperature. Simultaneously, another synthesis path for $\mathbf{3}$ was investigated. However, the abstraction of the phenyl groups of $\mathrm{O}\left(\mathrm{Si}_{2} \mathrm{Me}_{4} \mathrm{Ph}\right)_{2}$ (5) by trifluoromethanesulfonic acid was not successful so that this route was finally abandoned. ${ }^{10}$

In high dilution, the inorganic building block 3 reacts selectively with diethylene glycol and triethylamine $\left(\mathrm{NEt}_{3}\right)$ to the hybrid crown ether 1,2,4,5-tetrasila[12]crown-4 (6) (Scheme 3). Compound 6 is a highly viscous oil which is well miscible in DCM, THF and $n$-pentane, but only poorly miscible in water. Differently to the before described hybrid crown ethers like 1,2-disila[12]crown-4, no decomposition of $\mathbf{6}$ was observed in water. Ligand $\mathbf{6}$ incorporates three different types of $\mathrm{O}$ atoms, C, C/Si and $\mathrm{Si}$ substituted ones, which generates ideal conditions for comparing the respective coordination ability.

Lithium triflate, which is only poorly soluble in DCM, was the salt of choice. The complexation by compound 6 in DCM was successfully completed after $4 \mathrm{~h}$, resulting in a clear solution. Removal of the solvent led to a colourless solid, which gave colourless rods after recrystallization from DCM/cyclopentane. [ $\mathrm{Li}(1,2,4,5$-tetrasila[12]crown-4)OTf] (7) crystallizes in the orthorhombic space group Pbca with sixteen molecules per unit cell. Different to the free ligand $\mathbf{6}$, complex 7 is highly sensitive towards traces of water as has also been observed for other disila-crown ether complexes. ${ }^{7}$

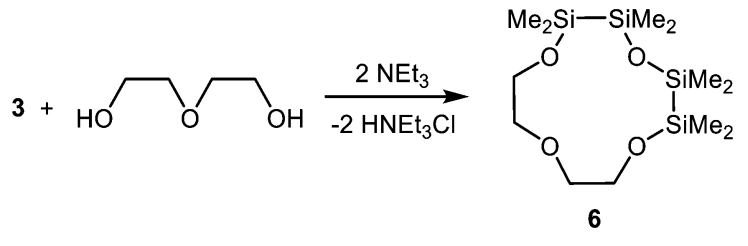

Scheme 3 Reaction path for ligand 6.

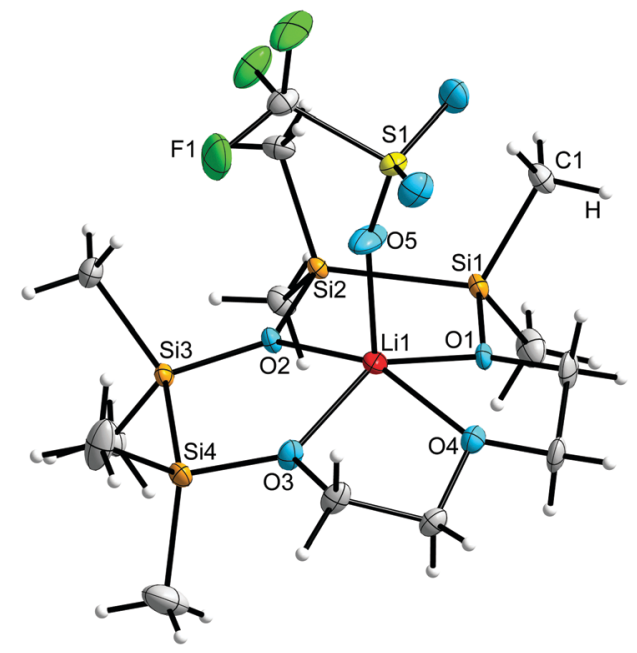

Fig. 2 Molecular structure of $\mathbf{7}$ in the crystal. Thermal ellipsoids represent the $50 \%$ probability level.

In complex 7, the lithium cation is coordinated by the four crown ether $\mathrm{O}$ atoms and one $\mathrm{O}$ atom of the trifluoromethanesulfonate anion $\left(\mathrm{OTf}^{-}\right)$, giving a coordination number of five (Fig. 2). The three different types of $\mathrm{O}$ atoms in the ligand show strong deviations in their bond lengths to $\mathrm{Li}^{+}$. While the completely $\mathrm{C}$ and the hybrid substituted $\mathrm{O}$ atoms $\mathrm{O} 4, \mathrm{O} 1$ and $\mathrm{O} 3$ establish similar bond lengths of 209.4(6) pm and 201.4(6) pm respectively, the fully $\mathrm{Si}$ substituted $\mathrm{O}$ atom $\mathrm{O} 2$ exhibits a considerably long bonding (231.0(6) pm, Table 1). These results, based on X-ray diffraction, differ from the calculated structure of $[\mathrm{Li}(1,2,4,5-$ tetrasila[12]crown-4)] $]^{+}$, wherein the anion has not been considered. As can be deducted from the bond lengths between $\mathrm{Li}^{+}$and the three types of $\mathrm{O}$ atoms, the cation is more centrally located, with the hybrid substituted $\mathrm{O}$ atoms showing the shortest and the $\mathrm{C}$ substituted $\mathrm{O}$ atom the longest bonding (Table 1). These deviations may be a result of the hydrogen bonding between the anion $\mathrm{F}_{3} \mathrm{CSO}_{3}{ }^{-}$and the $\mathrm{H}$ atoms of the methyl groups. The distance between one of the $\mathrm{H}$ and one $\mathrm{F}$ atom (260.0(2) pm) is beneath the sum of the van-der-Waals-radii. The orientation of $\mathrm{F}_{3} \mathrm{CSO}_{3}{ }^{-}$towards the methyl groups may push the cation in the direction of the carbon bonded $\mathrm{O}$ atom $(\mathrm{O} 4)$.

As expected, the presence of two disilane units leads to an increased diameter of the crown ether. The ring diameter affects beside the donor ability of the used anion - the position of the cation in the crown ether. For example in $\left[\mathrm{Li}([12]\right.$ crown-4)OTf $](8), \ddagger \mathrm{Li}^{+}$is located 83.6(9) pm above the plane generated by the ring systems' $O$ atoms. In the hybrid crown ether complex 7, the $\mathrm{Li}^{+}$cation is located only 56.8(4) pm above the plane of the ligands' $\mathrm{O}$ atoms, indicating a better matching with respect to the ring diameter. Moreover, the adjacent disilane units lead to an asymmetric structure of the ligand as a result of the mean Si-Si bond length of 233.8(1) pm and the comparatively smaller mean C-C bonding of 150.1(1) pm (Fig. 3). As reported before, $\mathrm{C}-\mathrm{O}-\mathrm{C}$ bond angles are generally smaller compared to $\mathrm{Si}-\mathrm{O}-\mathrm{Si}$ angles. ${ }^{11}$ In complex 7 , the bond angles widen in the series $\mathrm{C}-\mathrm{O}-\mathrm{C}<\mathrm{C}-\mathrm{O}-\mathrm{Si}<\mathrm{Si}-\mathrm{O}-\mathrm{Si}$ (Table 1).

As observed in the reported disila-crown ether complexes, the interaction $\mathrm{p}(\mathrm{O}) \rightarrow \sigma^{*}(\mathrm{Si}-\mathrm{C})$ can be observed with respect to 
Table 1 Selected bond lengths and angles of compound 7, the calculated cationic complex [Li@6 $]^{+}$and ligand 6

\begin{tabular}{|c|c|c|c|c|c|c|c|c|c|c|}
\hline \multirow[b]{2}{*}{ Compound } & \multirow[b]{2}{*}{ Method } & \multicolumn{6}{|c|}{ Selected bond lengths [pm] } & \multicolumn{3}{|c|}{$\underline{\text { Selected angles }\left[{ }^{\circ}\right]}$} \\
\hline & & $\mathrm{Li}-\mathrm{O}_{\mathrm{C}}{ }^{a}$ & $\mathrm{Li}-\mathrm{O}_{\mathrm{C} / \mathrm{Si}}^{b}$ & $\mathrm{Li}-\mathrm{O}_{\mathrm{Si}}^{c}$ & $\mathrm{Si}-\mathrm{O}_{\mathrm{C}}{ }^{a}$ & $\mathrm{Si}-\mathrm{O}_{\mathrm{Si}}^{c}$ & $\mathrm{Si}-\mathrm{C}$ & $\mathrm{C}-\mathrm{O}-\mathrm{C}$ & $\mathrm{C}-\mathrm{O}-\mathrm{Si}$ & $\mathrm{Si}-\mathrm{O}-\mathrm{Si}$ \\
\hline 7 & $\mathrm{XRD}^{d}$ & $209.4(6)$ & $201.4(6)$ & $231.0(6)$ & $167.2(2)$ & 166.7(1) & $185.8(5)$ & $113.6(2)$ & $123.4(2)$ & 134.3(1) \\
\hline$\left[\operatorname{Li}(1,2,4,5 \text {-tetrasila[12]crown-4) }]^{+}\right.$ & $\mathrm{DFT}^{e}$ & 207.1 & 197.1 & 201.6 & 171.3 & 170.8 & 187.3 & 114.8 & 123.6 & 129.1 \\
\hline 6 & $\mathrm{DFT}^{e}$ & - & - & - & 168.2 & 165.2 & 188.4 & 114.7 & 124.2 & 149.2 \\
\hline
\end{tabular}

the bond lengths changes between the calculated free ligand structure and the calculated complex. ${ }^{8}$ Compound 6 incorporates two types of $\mathrm{Si}$ bonded $\mathrm{O}$ atoms: completely $\mathrm{Si}\left(\mathrm{Si}-\mathrm{O}_{\mathrm{Si}}\right)$ or $\mathrm{Si}$ and $\mathrm{C}$ bonded $\left(\mathrm{Si}-\mathrm{O}_{\mathrm{C}}\right)$ oxygen atoms. As expected, the impact of the negative hyperconjugation is stronger in the $\mathrm{Si}-\mathrm{O}_{\mathrm{Si}}$ bond, which shows a considerable increase of the calculated bond length by complexation from $165.2 \mathrm{pm}$ in the free ligand to $170.8 \mathrm{pm}$ in the lithium complex. The impact is smaller for the $\mathrm{Si}-\mathrm{O}_{\mathrm{C}}$ bonds, which increase from $168.2 \mathrm{pm}$ to $171.3 \mathrm{pm}$ (Table 1). Simultaneously, the eight $\mathrm{Si}-\mathrm{C}$ bonds length show a minor decrease as a result of the complexation.

In the ${ }^{29} \mathrm{Si}\{\mathrm{H}\}$ NMR spectrum, the two signals show a considerable downfield shift from $\delta=0.9 / 10.9 \mathrm{ppm}$ in the free ligand to $9.4 / 15.9 \mathrm{ppm}$ in the complex, indicating a strong electron withdrawing effect through the complexation of $\mathrm{Li}^{+}$. The signal at $0.9 \mathrm{ppm}$ in the free ligand corresponds to the equivalent $\mathrm{Si}$ atoms Si2 and Si3 (Fig. 3), which undergo a downfield shift of $\Delta(\delta)=8.5 \mathrm{ppm}$, while Si1 and Si4 show a smaller shift of $\Delta(\delta)=5.0 \mathrm{ppm}$. This can be attributed to the stronger polarisation of the completely $\mathrm{Si}$ bonded $\mathrm{O}$ atom $\mathrm{O} 2$ in the solution, in comparison to the $\mathrm{Si} / \mathrm{C}$ bonded $\mathrm{O}$ atoms $\mathrm{O} 1$ and $\mathrm{O} 3$.

The relative binding affinity of 6 was studied by means of DFT, implemented in Turbomole V7.0.1, ${ }^{12}$ using the BP86 functional ${ }^{13}$ and the def2-TZVP basis set with inclusion of dispersion interactions. ${ }^{14}$ As presented in Scheme 4, the exchange of $\mathrm{Li}^{+}$from [12]crown-4 to the hybrid crown ether 6 releases $29.51 \mathrm{~kJ} \mathrm{~mol}^{-1}$. Particularly with respect to the before described constitution

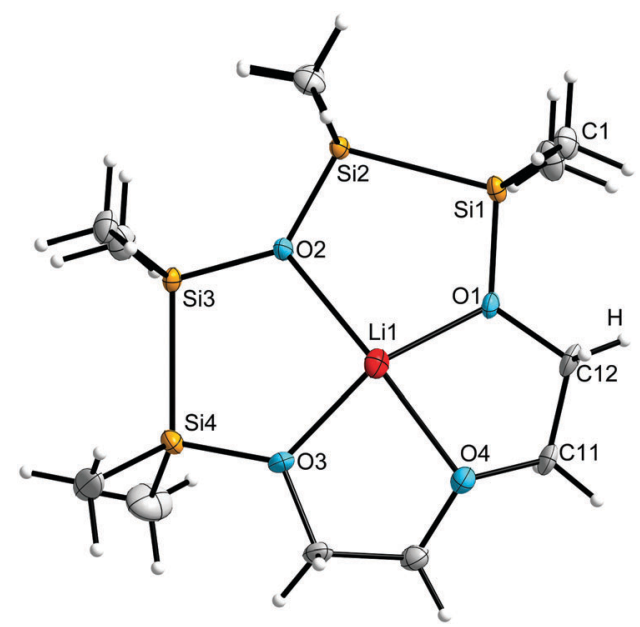

Fig. 3 A top-view of the molecular structure in the crystal of [Li(1,2,4,5tetrasila[12]crown-4)] $]^{+}$. The anion is not displayed. isomer 1,2,7,8-tetrasila[12]crown-4, ${ }^{7}$ the complexation ability of 6 is considerably high. Hybrid disila-crown ethers generally require an increased amount of energy for changing from the free ligand structure to the structure found within the complex compared to organic crown ethers. This can be related to the adoption of the ecliptic arrangement of the methyl groups in the complex, which has also been observed in cyclosiloxane complexes. ${ }^{6}$ The methyl groups in complex 7 also adopt an approximately eclipsed conformation with dihedral angles between $4.2(1)^{\circ}-13.5(1)^{\circ}$. This is not only the case between directly bonded $\mathrm{Si}$ atoms, but also consistently between the $\mathrm{O}$ bridged $\mathrm{Si}$ atoms $\mathrm{Si} 2$ and $\mathrm{Si} 3$.

Calculation of the energy differences $\Delta E_{\text {geom }}$ between the free and the complex geometries of 1,2,4,5-tetrasila[12]crown-4 (6) reveals a value of $69.89 \mathrm{~kJ} \mathrm{~mol}^{-1}$ (Scheme 5), which is $9.48 \mathrm{~kJ} \mathrm{~mol}^{-1}$ higher compared to the constitution isomer 1,2,7,8-tetrasila[12]crown-4. ${ }^{7}$ The increased amount of energy refers to the steric hindrance of the ecliptic Me groups between the $\mathrm{O}$ bridged disilane fragments. Although $\Delta E_{\text {geom }}$ is high, ligand 6 shows a considerably coordination ability (Scheme 4), which implies a significant electrostatic attraction between the completely $\mathrm{Si}$ substituted $\mathrm{O}$ atom and $\mathrm{Li}^{+}$. With respect to the before described complex stabilities of disila-crown ethers, ${ }^{7}$ the basicity of the $\mathrm{C}_{2} \mathrm{H}_{4}$ and/or $\mathrm{Si}_{2} \mathrm{Me}_{4}$ substituted $\mathrm{O}$ atoms increases in the series $\mathrm{O}_{\mathrm{C}}<\mathrm{O}_{\mathrm{Si} / \mathrm{C}}<\mathrm{O}_{\mathrm{Si}}$.

In conclusion, the synthesis of $\mathrm{O}$ bridged disilane fragments like $\mathrm{O}\left(\mathrm{Si}_{2} \mathrm{Me}_{4} \mathrm{Cl}\right)_{2}(3)$ provides access to $\mathrm{Si}$ based crown ethers. For this purpose, TCCA serves as versatile agent for the asymmetric chlorination of tetramethyldisilane. The hybrid crown ether $\mathbf{6}$ was obtained through reaction of $\mathbf{3}$ with diethylene glycol and incorporates three types of $\mathrm{O}$ atoms: completely $\mathrm{C}$, half $\mathrm{C}$ and $\mathrm{Si}$ and completely Si substituted ones. Complexation of lithium triflate yielded single crystals of [Li(1,2,4,5-tetrasila[12]crown-4)OTf] (7), which were characterized by X-ray diffraction. DFT calculations (BP86 functional and def2-TZVP basis set) revealed that the presence of the completely $\mathrm{Si}$ substituted $\mathrm{O}$ atom leads to a considerable increase of the coordination ability compared to [12]crown-4 as well as the hitherto known disila-crown ethers. ${ }^{7}$ The strong interaction between the lithium cation and the completely Si bonded $\mathrm{O} 2$ atom has also been confirmed by ${ }^{29} \mathrm{Si}$ NMR spectroscopy by reference to the significantly high downfield shift of the equivalent Si atoms Si2 and Si3.

$$
6+\{\mathrm{Li}[12] \text { crown }-4\}^{+} \stackrel{\Delta \mathrm{E}=-29.51 \mathrm{~kJ} / \mathrm{mol}}{\longrightarrow}[\mathrm{Li} @ 6]^{+}+[12] \mathrm{crown}-4
$$

Scheme 4 Relative energy for the lithium exchange from [12]crown-4 to 1,2,4,5-tetrasila[12]crown-4 (6) as obtained from DFT calculations. 


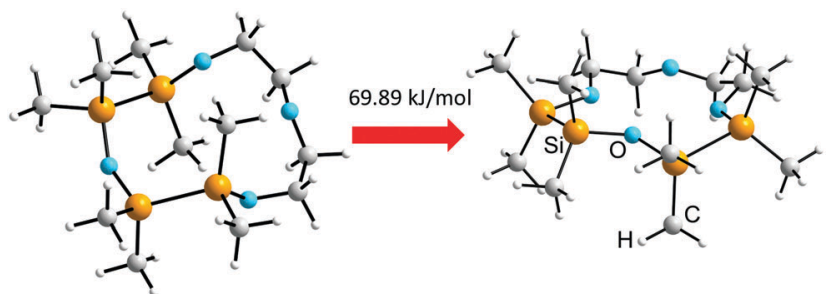

Scheme 5 Illustration of the transformation from the free ligand structure to the molecular structure found within the complex and the resulting energetic effort.

These results challenge the so far accepted theories concerning the low coordination ability of siloxanes. Negative hyperconjugation although present - doesn't significantly reduce the basicity of disila-crown ethers. Through insertion of disilane instead of monosilane fragments, the distance between the Si atoms and the metal cation is high enough to prevent electrostatic repulsion a major factor for the low coordination ability of cyclosiloxanes. ${ }^{6}$ The synthesis and complexation of completely disilane based crown ethers will give further insights into the coordination ability of Si bonded $\mathrm{O}$ atoms, which is still a matter of ongoing research.

This work was financially supported by the Deutsche Forschungsgemeinschaft (DFG). G. T. thanks the Leopoldina Nationale Akademie der Wissenschaften for a postdoctoral scholarship.

\section{Notes and references}

\$ For details concerning compound 8 see ESI. $\dagger$

1 (a) H. J. Emeléus and M. Onyszchuk, J. Chem. Soc., 1958, 604; (b) R. West, L. S. Whatley and K. J. Lake, J. Am. Chem. Soc., 1961,
83, 761; (c) B. D. Shepherd, J. Am. Chem. Soc., 1991, 113, 5581; (d) C. von Hänisch, O. Hampe, F. Weigend and S. Stahl, Angew. Chem., Int. Ed., 2007, 46, 4775; (e) U. Dittmar, H. C. Marsmann and E. Rikowski, in Organosilicon Chemistry Set: From Molecules to Materials, ed. N. Auner and J. Weis, Wiley-VCH Verlag GmbH, Weinheim, Germany, 2005, ch. 64b.

2 (a) A. Decken, J. Passmore and X. Wang, Angew. Chem., Int. Ed., 2006, 118, 2839; (b) J. S. Ritch and T. Chivers, Angew. Chem., Int. Ed., 2007, 46, 4610.

3 F. Weinhold and R. West, J. Am. Chem. Soc., 2013, 135, 5762.

4 (a) R. J. Gillespie and S. A. Johnson, Inorg. Chem., 1997, 36, 3031; (b) J. Passmore and J. M. Rautiainen, Eur. J. Inorg. Chem., 2012, 6002.

5 S. Grabowsky, M. F. Hesse, C. Paulmann, P. Luger and J. Beckmann, Inorg. Chem., 2009, 48, 4384.

6 (a) A. Decken, F. A. LeBlanc, J. Passmore and X. Wang, Eur. J. Inorg. Chem., 2006, 4033; (b) T. S. Cameron, A. Decken, I. Krossing, J. Passmore, J. M. Rautiainen, X. Wang and X. Zeng, Inorg. Chem., 2013, 52, 3113.

7 K. Reuter, M. R. Buchner, G. Thiele and C. von Hänisch, Inorg. Chem., 2016, 55, 4441.

8 M. Ouchi, Y. Inoue, T. Kanzaki and T. Hakushi, Bull. Chem. Soc. Jpn., 1984, 57, 887.

9 (a) S. Varaprath and D. H. Stutts, J. Organomet. Chem., 2007, 692, 1892; (b) T. Hafner, Master thesis, TU Graz, 2013.

10 Experimental details on the synthesis of $\mathrm{PhSi}_{2} \mathrm{Me}_{4} \mathrm{Cl}$ (4) and $\mathrm{O}\left(\mathrm{Si}_{2} \mathrm{Me}_{4} \mathrm{Ph}\right)_{2}(5)$ can be found in the $\mathrm{ESI}^{\dagger}$.

11 S. Shambayati, J. F. Blake, S. G. Wierschke, W. L. Jorgensen and S. L. Schreiber, J. Am. Chem. Soc., 1990, 112, 697.

12 Turbomole Version 7.0.1, Turbomole GmbH 2016. Turbomole is a development of University of Karlsruhe and Forschungszentrum Karlsruhe 1989-2007, Turbomole GmbH since 2007.

13 (a) F. Weigend and R. Ahlrichs, Phys. Chem. Chem. Phys., 2005, 7, 3297; (b) F. Weigend, Phys. Chem. Chem. Phys., 2006, 8, 1057; (c) M. Dolg, H. Stoll, A. Savin and H. Preuss, Theor. Chim. Acta, 1989, 75, 173; (d) H. Stoll, B. Metz and M. Dolg, J. Comput. Chem., 2002, 23, 767.

14 (a) S. Grimme, J. Antony, S. Ehrlich and H. Krieg, J. Chem. Phys., 2010, 132, 154104; (b) S. Grimme, S. Ehrlich and L. Goerigk, J. Comput. Chem., 2011, 32, 1456. 